\title{
COLABORAÇÃO (DELAÇÃO) PREMIADA - A PROBLEMÁTICA ACERCA DA LEGITIMIDADE E CONSTITUCIONALIDADE
}

\section{ARTIGO ORIGINAL}

COSTA, João Maurício De Jesus ${ }^{1}$

RAIMUNDO, Stela Do Couto ${ }^{2}$

COSTA, João Maurício De Jesus. RAIMUNDO, Stela Do Couto. Colaboração (delação) premiada - A problemática acerca da legitimidade e constitucionalidade. Revista Científica Multidisciplinar Núcleo do Conhecimento. Ano 04, Ed. 12, Vol. 03, pp. 24-37. Dezembro de 2019. ISSN: 2448-0959

\section{RESUMO}

O objetivo deste estudo é entender a relação entre o instrumento da colaboração premiada e sua legitimidade legal diante do arcabouço jurídico-constitucional e o moral dos olhares social e doutrinário, vez que para obter as benesses da delação premiada é necessário colaborar e isso significa abrir mão de garantias e direitos constitucionais, além de ser uma escolha moralmente reprovável por aquele que pretende se beneficiar oferecendo outrem ao poder estatal responsável por investigar, denunciar e julgar. Posto isso, é necessário analisar se enquanto um indivíduo utilizase de direitos e garantias fundamentais e constitucionais para negociar redução ou até mesmo isenção de pena diante de crimes praticados é ou não legítimo e

\footnotetext{
1 Pós-graduado no curso de Direito Penal e Direito Processual Penal da rede de ensino Luiz Flávio Gomes - LFG; MBA em Gestão de logística Internacional pela Associação Brasileira de Comércio Exterior; Global Management pela Massachusetts Institute of Business - MIB; Pós-graduando em Direito Constitucional e Tributário pela Faculdade Metropolitana do Estado de São Paulo - FAMEESP; Bacharel em Direito pela Instituição Paraibana de Ensino Renovado - INPER.

2 Especialização em Direito Penal e Processo Penal. Graduação em Direito.
} 
constitucional. Identificar em qual ordenamento jurídico oriunda o instrumento colaboração (delação) premiada e como se propagou, bem como definir as possíveis causas de aumento da utilização deste instrumento. O resultado alcançado mira no fato de que nos últimos anos o instrumento da colaboração premiada foi utilizado de sobremaneira tendo em vista o aumento das prisões preventivas e condenações de criminosos que orbitam o chamado crime de colarinho branco e estes iniciaram a busca por liberdade o quanto antes. Números apontam que as colaborações saltaram para de 20 (vinte), para mais de 150 (cento e cinquenta) em 25 (vinte e cinco) anos. Concluímos, portanto, que de fato determinados princípios, garantias e direitos constitucionais foram mitigados em nome de outra garantia constitucional, qual seja, a liberdade e posto desta forma cabe somente aquele que cometeu o crime sopesar se em nome da liberdade. Os resultados angariados delimitam com clareza solar que o uso vertiginoso da delação premiada ainda é adstrita as pessoas que residem nas classes mais abastarda da sociedade e que seu uso se tornou corriqueiro dentre outros motivos pela sanha em não cumprir a pena estatal imposta como qualquer outro cidadão teria.

Palavras-chave: Delação premiada, aspectos constitucionais, legitimidade.

\section{INTRODUÇÃO}

O presente trabalho científico tem por finalidade mostrar a importância do instrumento da colaboração premiada, bem como obter maiores informações acerca do aumento na utilização do instituto e sua questionada legalidade/constitucionalidade diante de tantas críticas e debates em torno, levando-o como necessidade extrema melhor aprofundamento da matéria diante de um Estado ineficiente nas suas obrigações. Como por exemplo, a segurança pública com aparato suficiente para combater efetivamente a criminalidade e o bom uso da colaboração premiada para atingir crimes até então muito bem praticados longe do olhar estatal.

Cristalino é que o Estado, detentor de riquezas e fontes de renda deveria ser melhor preparada para o combate sobre a criminalidade, seja ele de baixo ou de grande prejuízo (patrimonial ou não, estatal ou não). Embora aparente ser uma luta desigual 
entre o Estado e criminosos, este primeiro não está conseguindo prevalecer face ao segundo em organização e estratégia, muito embora essa situação se vislumbra diante de uma ineficiência dos governantes e legisladores que lá estão.

Diante de tamanha inércia, o que pensou o legislador brasileiro? Utilizar-se da existência do direito comparado, e nesse diapasão o do direito norte-americano, para inserir um instrumento chamado de colaboração (delação) premiada no ordenamento jurídico com a finalidade de banir organizações criminosas e identificar seus membros, combater a criminalidade e utilizar menos recursos do Estado para isso tudo. Dessa forma, vantagens são oferecidas aos colaboradores para que estes informem pessoas, caminhos, meios e provas como crimes são praticados.

O quadro inicialmente apresentado traz à baila o objeto deste trabalho científico que se voltará em analisar quando o indivíduo utiliza-se de direitos e garantias fundamentais e constitucionais para negociar redução ou até mesmo isenção de pena diante de crimes praticados é ou não legítimo e constitucional.

Quanto ao personagem colaborador, a este utiliza-se dos meios que possui para garantir a melhor barganha possível diante dos crimes perpetrados, inclusive seus direitos, garantias e princípios constitucionais, não dizendo com isso que está infringindo a Norma Suprema. Óbvio que questionamentos da ordem moral e ético avassalaram, mas aí não é um problema estatal e sim pessoal, embora quem delinquiu deveria rever seus valores antes.

Para alcançar o desiderato científico proposto, foi utilizada a metodologia de pesquisa descritiva com abordagem qualitativa e do tipo revisão de literatura. A escolha desse método se deu em função da delimitação do tema, isto é, traçou-se o objeto de estudo conforme afinidade com o assunto, o objetivo e o problema da pesquisa.

Assim, por ter caráter descritivo, pode ser conceituado por "narrar, expor, contar, detalhar" descrevendo um fato, ação ou indivíduo. (BUENO, 1996). O estudo descritivo visa, em termos gerais, identificar as representações sociais e o perfil de indivíduos e grupos, como também identificar estruturas, formas, funções e conteúdo. 
No que tange à abordagem qualitativa, o pesquisador interpreta os fatos, procurando solução para o problema proposto.

Pretende-se compreender como nasce o instrumento colaboração premiada, como chegou ao ordenamento jurídico brasileiro, o porquê do aumento da utilização deste meio e se ele é legítimo e constitucional diante da Corte Suprema do Poder Judiciário Brasileiro.

Para compor o referencial teórico, foram encontrados 38 materiais por meio do descritor controlado colaboração and premiada e 61 trabalhos utilizando o descritor delação and premiada. A partir dos critérios de exclusão, foram selecionados 26 materiais dentre livros, artigos e dissertações. Para a coleta de dados, os critérios de inclusão foram trabalhos que estivessem na língua portuguesa, que compreendessem o período a partir do ano 2006 até Setembro de 2017 e que estivessem disponíveis na íntegra. Já os critérios de exclusão foram artigos repetidos e aqueles que após a leitura dos resumos não fossem pertinentes ao tema.

Assim, a escolha dos artigos se deu primordialmente pela leitura exploratória dos títulos e respectivos resumos, em busca da aproximação com o tema desse estudo. Feito isso, seguiu-se com a leitura seletiva, analítica e interpretativa para relacionar o conteúdo dos materiais encontrados com objetivo da pesquisa, ao passo que essa técnica permitiu a análise dos dados segundo a categoria temática, sendo posteriormente fichados e organizados em tabelas para facilitar a análise de conteúdo.

\subsection{COLABORAÇÃO PREMIADA NO MUNDO}

Presente nas mais diversas normas legislativas pátria, o instituto da colaboração premiada, segundo bem retrata Marcos Paulo Santos Dutra, teve seu nascimento no direito norte-americano e se deu em um período de forte política criminal que veio a ser chamado Law and Order (Lei e Ordem). Com o passar do tempo, tentando trazer algo que fosse novo no combate aos crimes e organizações existentes, observou-se que foi introduzido no ordenamento jurídico-penal brasileiro na década de 90 onde 
pairava um apego legislativo ao populismo penal, a exemplo da Lei de Crimes Hediondos.

Ressaltam que muito embora figure como algo novo, na prática não era algo totalmente novo tendo em vista que o direito penal brasileiro já desfrutou de antecedentes vindos das Ordenações Filipinas (1603-1830) que emanavam no sentido da colaboração (delação) premiada. (SANTOS, 2017).

Dessa forma, colaboração (delação) não é algo inovador, nem oriunda sua base no direito norte-americano, mas no modelo Filipino.

Contudo, os legisladores que quiseram aproveitar a forte onda de reprimenda que abarcava o país, bem como utilizar como instrumento a colaboração (delação) para fomentar ações do Estado de política de segurança pública, ao qual, diga-se de passagem, embora seja um Estado forte, este não investia o necessário para que aparatos e órgãos estatais reprimissem o crime como deveria e na resposta que se esperava. Passando a adotar no Brasil a base da colaboração premiada norteamericana, a qual serão dados maiores comentários por sua importância.

A fraqueza do Estado em envidar de forma eficiente o combate ao crime fez este se tornar maior, mais organizado e mais desenvolvido, ao passo que em lado contrário ocorre sistematicamente o desmantelamento dos órgãos de repressão ao crime, seja ele o pequeno delito, seja ele o crime organizado.

Heráclito Antônio Mossin (2016) verifica e atesta que diante da própria incompetência do Estado, diante do aproveitamento legislativo de países que desfrutam de outra realidade constitucional, penal, legislativo e social, o legislador brasileiro buscou alternativa para que o Estado obtivesse resultado expressivo sem necessariamente demandar de mais recursos. Ou seja, compensa-se o criminoso colaborador (delator), oferecendo a este a oportunidade de permutar com o Estado seus direitos e garantias constitucionais para que com isso obtenha vantagens.

Se a origem norte-americano do instituto for observada, é possível ver que ele é utilizado em um sistema judicial diverso do brasileiro. O fato do Brasil importar 
legislação sem adequar corretamente ao sistema aqui encontrado pode não ser tão producente quanto se imagina.

O sistema jurídico norte-americano, integrante da common law, é muito pragmático. Diferentemente do sistema romano-germânico, a doutrina não se preocupa em dogmatizar ou teorizar o direito, mas sim em sistematizar a sua aplicação aos casos concretos. Isso é bastante compreensível, uma vez que, na common law, as normas jurídicas surgem do caso particular - leading case - para o geral, e não o contrário. (SANTOS, 2017).

Nos últimos anos o sistema common law vem bebendo da fonte do sistema romanogermânico, vez que vem passando por processo de codificação na Inglaterra e no próprio Estados Unidos da América. Importante salientar que o sistema romanocontinental tem servindo-se da mesma fonte do sistema consuetudinário, e da justiça consensual penal.

Dito isso, observa-se claramente que não se consegue vislumbrar a existência no direito norte-americano à existência de princípios tais como 0 da obrigatoriedade ou da oportunidade no que diz respeito a ação penal pública. Outrossim, por existir um direito penal negocial nos Estados Unidos, os promotores de justiça têm liberdade total para negociar com os criminosos sobre suas penas e não só isso, lá a atividade policial, a jurisdicional e até na execução da pena emerge tal oportunidade.

Em primeira leitura pode parecer contraditório pensar em combater a criminalidade barganhando desde o oferecimento de denúncia até a execução penal, mas o que se faz lá nada mais é do que razões de políticas criminais existentes. Pensam que agilizando situações de menor potencial ofensivo ao particular ou ao Estado podem focar em atividades criminosas mais relevantes e que demandam atenção por parte do(s) governo(s) já que o Estado não pode demonstrar fraqueza e aplicar penas significativas para que a sociedade veja que não compensa delinquir. Por óbvio que nem tudo são maravilhas nesta particular possibilidade do direito penal negocial, já 
que cada caso é um caso e, embora possam parecer idênticos, o Estado poderá aplicar sanções diferenciadas.

Outro problema de natureza gravíssima identificado pela pesquisa estadunidense é no tocante ao réu inocente, conhecido como plea bargaining. Por incrível que pareça, réus se declaram culpados apenas para conseguirem barganhar com a promotoria e impedirem a condenação mais pesada. Isso não é apenas para constar em livros ou artigos - diversos são os casos conhecidos visto que são amplamente divulgados pela mídia que os cobre e, por muitas das vezes, acaba ingerindo-se nos resultados dos julgamentos -

Atrelado a tudo isso, são encontradas ainda situações que ensejam ou não a persecução penal nos Estados Unidos baseada em discriminação racial, ou persecução penal seletiva, o impacto discriminatório que acaba impondo à vítima o dever de demonstrar que em caso análogo o julgamento obteve final diferente, 0 escopo discriminatório. Ou seja, o direito penal negocial tem suas benesses, mas também traz seus fardos existenciais, que em muitas das vezes causam prejuízos consideráveis aos jurisdicionados inocentes.

Dutra (2017) mais uma vez, de forma brilhante, retrata que a Suprema Corte Norte Americana é tão confiante no Estado e suas instituições que ignora a existência categórica da relativização das garantias constitucionais, baseando-se na obra Contrato Social de Hobbes e Locke.

Com isso, os promotores de justiça detêm total poder negocial não podendo sofrer interferência ou controle do poder judiciário, devendo suas negociações prevalecerem. Dessa forma, a depender do Estado, quem regula a política criminal são os promotores de justiça. Que fique claro: quando a transação penal sugere um tipo de sentença, seja por parte da acusação ou por parte da defesa, o juiz é livre para decidir, inclusive podendo agravar a pena que será cominada. Dessa forma, é necessário observar a diferença entre um acordo ou uma sugestão de sentença. 
Para se realizar um acordo de colaboração premiada o acusado deve fazer de forma voluntária, livre de ameaça, violência ou promessas falsas, sendo inquirida de sua voluntariedade por juiz em audiência. Ademais, outros requisitos devem ser observados pelo juízo, como por exemplo a advertência pessoal e necessária que fará ao acusado garantindo que este compreendeu todo o acordo celebrado.

\subsection{COLABORAÇÃO PREMIADA NO BRASIL}

Como não poderia deixar de ser, no direito penal negocial existe a renúncia das garantias processuais, o que no Brasil não foi introduzido. Questionável não introduzir a renúncia processual, mas acolher renúncia de garantia constitucional visto que diversas garantias processuais também são constitucionais (no ordenamento jurídico brasileiro). É o que se pode denominar caricatamente de "direito penal negocial de fato brasileiro". Ou seja, implementa-se quase tudo da legislação alienígena, mas só uma parte porque o todo não é possível.

No Brasil, embora presente desde 1990, foi apenas em 2013 que o instituto da colaboração (delação) premiada ganhou notoriedade. Isso não quer dizer que anteriormente a este ano não se tenha utilizado tal ferramenta, muito pelo contrário. Só no caso conhecido como BANESTADO em que envolveu o envio de mais de \$134 bilhões de dólares para fora do país, foram celebrados algo em torno de 21 acordos. (Valor Econômico, Legislação \& Tributos, p. E1). Ainda assim, não tinha ganho aquela época a notoriedade dos dias atuais com a denominada "Operação Lava Jato", em que se acompanha os inúmeros doleiros, políticos e empresários donos de fortunas e conglomerados sendo presos preventivamente.

Com isso, dizem alguns juristas atuantes na esfera criminal, passou-se a forçar a adesão de acordos de colaboração premiada para que criminosos maiores que aqueles ou na identificação de um maior número de criminosos fossem alcançados, as colaborações saltaram para mais de 150 (cento e cinquenta) em 25 anos desde as primeiras colaborações premiadas registradas. 
A colaboração (delação) premiada não está somente na Lei das Organizações Criminosas. Ela está presente em diversos diplomas legais como Lei de Crimes Hediondos/ 1999, Lei Antitruste/ 2011, Lei Anticorrupção/ 2013, Lei de Drogas/ 2006, dentre outras.

Com essas informações iniciais acerca da existência do instituto da delação, hodiernamente é fácil perceber que o número de delações premiadas nos últimos anos têm ganhado volume, tornando-se tão constante no dia a dia em vista das prisões e condenações de praticantes do chamado pela criminologia de "crime de colarinho branco", ou seja crime cometido por uma pessoa respeitável, que obteve educação de qualidade, oportunidades e de alta posição social, não muitas das vezes executivos, políticos ou influenciadores sociais.

Assim, diante da eminência de perder toda regalia que o dinheiro e o status social podem oferecer, estes não suportaram ou suportariam a vida dura e penosa na carceragem de uma delegacia ou de uma penitenciária, onde consta uma população carcerária brasileira atualmente de 711.463 presos (CNJ, s.d.).

Contudo, para alguns a delação é um meio de buscar salvar-se de um sistema prisional deficitário - onde a realidade não chega perto da vida que os delatores viviam -, iniciando a barganha de direitos e garantias constitucionais, que em tese, não deveriam ser negociadas e passam a ser o maior trunfo de quem deseja obter informações que levem a algo maior sem que o Estado tenha que desempenhar papel relevante para conseguir.

\section{DIREITOS E GARANTIAS CONSTITUCIONAIS}

Aqui, remetem tanto aos direitos como as garantias constitucionais, entretanto, são palavras com o mesmo significado?

Assim, os DIREITOS são bens e vantagens prescritos na norma constitucional, enquanto as GARANTIAS são os instrumentos através dos quais se assegura 0 exercício dos aludidos direitos 
(preventivamente) ou prontamente os repara, casos violados. (LENZA, 2014, p.1059).

O direito constitucional ao silêncio do preso por exemplo, previsto no artigo $5^{\circ}$, inciso LXIII da CRFB de 1988, não é possível dentro de um acordo de delação, mas tem que ser um ato espontâneo, que parte da vontade do indivíduo criminoso. Esse direito ao silêncio está esposado no pacto de São José da Costa Rica, do qual o Brasil é signatário.

A título de melhor compreensão, o criminoso não é obrigado a confessar, por força de garantia judicial internacional, assim como pela constituição do país, mas se quiser utilizar desta quebra de silêncio para barganhar sua liberdade ou outras cláusulas que Ihe beneficiem é plenamente possível e constitucional. Embora diga-se que seja imoral, antiético e outros, mas é um artifício de grande valia, não com razão, para quem cometeu crime e precisar permutar por benefícios.

Além do mais, alguns princípios também são colocados à baila quando da aceitação da colaboração.

O princípio da dignidade humana (art. $1^{\circ}$, inciso III, CF), tem por finalidade precípua unificar os direitos e garantias fundamentais e é visto como algo destinado diretamente ao valor moral e espiritual de cada indivíduo, caracterizado externamente como sua manifestação de vontade sendo exposta e fazendo-se valer. Pontuam por vez que é bastante limitada a restrição do usufruto dos direitos fundamentais.

Ao Estado só cabe promover meios para que tal princípio seja garantido e produza efeitos em sua plenitude. Dessa forma, quando se realiza um acordo de colaboração (delação) premiada, afastar esse princípio não é uma opção, ele deve ser inserido para garantir pelo menos a efetividade do indivíduo.

Já se referindo acerca do princípio da proporcionalidade, diversos doutrinadores apontam a existência deste nos termos de acordos em relação a pena agride o princípio em tela. Contudo, já foi superado a ideia de que a simples existência da quebra do princípio da proporcionalidade seja determinante para configurar a 
inconstitucionalidade, já que ao colaborar (delatar) ele se coloca em risco e a todos que o rodeia, por isso a redução ou perdão da pena se mostra coerente a outros pontos de vista, mas como observado por Costa:

A aplicação da mesma pena aos agentes, (...) representa ofensa à condição humana, atingindo-o, de modo contundente, na sua dignidade de pessoa. Existe uma dificuldade para que esse princípio possa ser viabilizado, ou seja, não há um critério que seja útil como medida de proporcionalidade. Esse critério deve ser buscado em um juízo de adequabilidade entre a gravidade do preceito sancionatório e a danosidade social do comportamento incriminado. E é claro que aquele que colaborou com a justiça por meio da delação causou uma menor danosidade social, razão pela qual deve receber uma redução de sua pen a em relação a seus comparsas (COSTA; s.p; s.d).

Ora, se de um lado existe o criminoso querendo barganhar seus direitos e garantias constitucionais, do outro existe o Estado desejando minimizar a utilização de sua estrutura para alcançar seu intento em desmantelar a organização criminosa e cessar a atividade ilícita. Nesse diapasão teriam algum embate entre o direito e garantia do ser humano e interesses do Estado?

Embora haja de fato um "balcão de negócios", esses direitos e garantias podem ser flexibilizados em detrimento de uma livre disposição do criminoso. Ou seja, ele está fazendo tal acordo abrindo mão de algo para ser beneficiado em situação em que ele teria de arcar com o ônus de uma atividade criminosa perpetrada.

Se existe todo o procedimento dito acima, a livre manifestação em transacionar o melhor acordo possível mesmo que para isso coloque como "forma de pagamento" seus direitos e garantias, é questionável moralmente? Sim, até hoje existe forte discussão sobre isso entre juristas e doutrinadores, mas não é ilegal e muito menos inconstitucional. 


\subsection{DIVERGÊNCIAS DOUTRINÁRIAS}

Damásio de Jesus (1999), defende a tese de que a delação premiada é algo maléfico ao direito penal e aos direitos e garantias constitucionais já que vai de encontro com preceitos morais irrenunciáveis.

Grande expoente e mestre do direito penal, o argentino Zaffaroni se manifesta da seguinte forma:

A impunidade de agentes encobertos e dos chamados 'arrependidos' constitui uma séria lesão à eticidade do Estado, ou seja, ao princípio que forma parte essencial do Estado de Direito: o Estado não pode se valer de meios imorais para evitar a impunidade [ . . . o Estado está se valendo da cooperação de um delinquente, comprada ao preço da sua impunidade para 'fazer justiça', o que o Direito Penal liberal repugna desde os tempos de Beccaria (ZAFFARONI, 1996, p. 45).

Já permeia nos debates acerca do tema a possibilidade de estender o benefício da colaboração (delação) premiada e de fato vem ganhando apoio de alguns juristas e doutrinadores. Estes afirmam que a utilização do instituto se fundamenta em princípios da moral e da ética, uma vez que o colaborador (delator), aparentemente, em total arrependimento do crime praticado e, dessa forma, através deste instrumento, tenta redimir-se perante a sociedade contribuindo com os órgãos responsáveis.

Além de Damásio de Jesus, o doutrinador Luiz Flávio Gomes rebate o posicionamento acima exposto afirmando que o ético e moral não poderia sobrepor aos interesses da sociedade de tão grave e desprezível que o instrumento revela do ser humano autor do fato criminoso, justamente por abrir mão de seus valores. O que não implica dizer que não o fez quando delinquiu, mas delatar terceiros soa, para estes autores, como repugnante. 
O princípio Nemo tenetur se detegere também possui forte presença nesse tipo de acordo e tem papel ímpar diante da exclusão do pressuposto da confissão para a eficácia da delação.

Essa observância deverá ser irrestrita, vez que ele, o princípio, está presente no diploma supra do ordenamento jurídico e tem presença marcante em outros diplomas alienígenas. Dessa forma, o princípio Nemo tenetur se detegere, em relação a delação premiada, terá que ser de amplo conhecimento do colaborador de todas as situações benéficas e também suas obrigações ao acordar com o órgão responsável.

Vale o reforço, em tempo, de que a confissão deverá ser sempre de livre manifestação de vontade e com total conhecimento do colaborador dos direitos e das obrigações a partir daquele momento assumido. Registra-se que as declarações do colaborador devem ser acompanhadas de indícios de provas ou provas diversas para que tenha sustentáculo positivo para efetivar o acordo não bastando, portanto, o apenas relatar sem ter como provar ou ao menos indicar.

Não há espaço para debate sobre ética, traição ou moral à vista da aplicação da colaboração premiada, pois a prática criminosa grave ofendeu primeiro tais nobre princípios. Ademais, o STF já reconheceu a constitucionalidade da colaboração (ou delação) premiada como meio de prova, o que fulmina qualquer tentativa de se doutrinar no sentido contrário (HC 99736/DF - Rel. Min. Ayres Britto, Julgamento 27/4/2010, Primeira Turma).

Por fim, o instrumento da colaboração não permite se valer do direito de não produzir prova contra si mesmo e no princípio da prova ilícita, sendo que a delação premiada guardada as devidas proporções é por muitas das vezes comparado ao período inquisitorial da Igreja Católica, quando a confissão deveria ser feita a qualquer custo e quando não havia o direito ao silêncio. 


\section{CONCLUSÃO}

Portanto, foi possível constatar que o instrumento da colaboração premiada não se apresenta revisto de inconstitucionalidade por sopesar princípios, garantias e direitos constitucionais em detrimento de outros princípios, garantias e direitos constitucionais estarão do outro lado da balança. Ou seja, caberá ao colaborador verificar se aquele acordo posto atende às suas necessidades, claro, sempre levando-se em consideração que deve ser um acordo também interessante para o ente estatal e que traga resultados maiores do que os alcançados até então.

Os estudos realizados demostraram que o aumento de sua aparição no direito brasileiro se deu indubitavelmente pelas prisões e condenações de criminosos da elite brasileira, pessoas que se utilizavam de toda uma estrutura de poder econômico/financeiro e político para a prática de atos delituosos, mas que não estão dispostos a cumprirem suas penas, pelo menos em sua totalidade, no sistema penitenciário brasileiro e a mazela que o acompanha.

Diante de todo o exposto, percebeu-se que por ter encontrado respaldo constitucional e diante dos trabalhos dos entes estatais encarregados de investigar, denunciar e de julgar que veio a se intensificar nos últimos anos em especiais com os casos denominados "mensalão" e "petrolão", alcançando criminosos do colarinho branco, até aqui a delação se apresenta como um belíssimo instrumento se bem utilizado pelo Estado no afã de estancar ou minimizar os crimes perpetrados. Claro, moralmente e diante da sociedade pode se apresentar como algo desprezível, entretanto não podemos aniquilar as benesses que o instrumento apresenta, embora seja respeitável sua divergência e falta de consenso social.

\section{REFERÊNCIAS}

ARANHA, Adalberto José de Camargo. Da prova no processo penal. 7. ed. rev. e atual. São Paulo: Saraiva, 2006. 
ARANHA, Adalberto José Q. T. de Camargo. Da prova no Processo Penal. 4 ed., São Paulo: Saraiva, 1996, p. 110 apud GUIDI, José Alexandre Marson. Delação Premiada no combate ao crime organizado. Franca: Lemos \& Cruz, 2006, p. 97.

Brayner, Yan Rêgo. O princípio do "nemo tenetur se detegere" e suas decorrências no processo penal. Disponível em: < https://jus.com.br/artigos/34665/o-principio-do-nemo-tenetur-se-detegere-e-suasdecorrencias-no-processo-penal>. Acesso em: 10 de Agosto de 2017.

BITTENCOURT, Cezar Roberto. Delação premiada na "Lava Jato" está eivada de inconstitucionalidades. Disponível em: <http://www.conjur.com.br/2014-dez04/cezar-bitencourt-nulidades-delacao-premiada-lava-jato>. Acesso em: 10 de Agosto de 2017.

CARTA FORENSE. Delação premiada: posição favorável. Disponível em: $<$ http://www.cartaforense.com.br/conteudo/artigos/delacao-premiada-posicaofavoravel/13614>. Acesso em 14 de agosto de 2017.

CERVINI, Raúl; GOMES, Luiz Flávio. Crime organizado: enfoque criminológico, jurídico e politico-criminal. São Paulo: Revista dos Tribunais, 1995.

COSTA, Marcos Dangelo da. Delação Premiada. Disponível em: http://www.conteudojuridico.com.br/monografia-tcc-tese,delacaopremiada,22109.html. Acesso em: 08 agosto 2017.

CUNHA, Rogério Sanchez; TAQUES, Pedro; GOMES, Luiz Flávio. Limites constitucionais da investigação. São Paulo: Revista dos Tribunais, 2009.

JESUS, Damásio de. 0 estágio atual da delação premiada no direito brasileiro. Disponível em:http://jus.com.br/artigos/7551/estagio-atual-da-delacao-premiada-nodireito-penal-brasileiro. Acesso em: 08 de Agosto de 2017.

JESUS, Damásio E. De. Perdão Judicial - colaboração premiada análise do art. 13 da Lei 9.807: primeiras ideias. Boletim IBCCRIM. São Paulo, v.7. N.82, Set. 1999. 
LEAL, Magnólia Moreira. A delação Premiada: um questionável meio de provas frente aos princípios e garantias constitucionais. Disponível em: https://www.jurisway.org.br/monografias/monografia.asp?id_dh=7663. Acesso em: 11 de Agosto de 2017.

MARQUES, José Frederico. Tratado de direito penal. São Paulo, Saraiva, 1961.

MINISTÉRIO DA JUSTIÇA. Lavagem de dinheiro. Brasil apresenta experiências de cooperação jurídica à ONU. mj.gov.br Brasília, 2008. Disponível em: /data/Pages/MJ5B0F1FEFITEMIDB6FE2D262CAF4842B10AE648ECB8E862PTBRI E.htm. Acesso em: 11 de agosto de 2017.

MOSSIN, Heráclito; MOSSIN, Júlio César G. Delação premiada - aspectos jurídicos. São Paulo: JH Mizuno, 2016.

NUCCl, Guilherme de Souza. Código Penal Comentado. 10ª Ed. São Paulo, Revista dos Tribunais, 2010.

NETO, José André Nunes. A Lei de drogas (11.343/06) e a (in)constitucionalidade da delação premiada. Disponível em: https://jus.com.br/artigos/57262/a-lei-de-drogas11-343-06-e-a-in-constitucionalidade-da-delacao-premiada. Acesso em: 11 de agosto de 2017.

Passarelli, Thaís dos Reis Andrade. Delação premiada frente a Operação Lava Jato. Disponível em: https://jus.com.br/artigos/47679/delacao-premiada-frente-a-operacaolava-jato. Acesso em: 11 de Agosto de 2017.

PORTAL CNJ. CNJ divulga dados sobre nova população carcerária brasileira. Disponível em: http://www.cnj.jus.br/noticias/cnj/61762-cnj-divulga-dados-sobrenova-populacao-carceraria-brasileira. Acesso em: 11 de Agosto de 2017.

Pierin, Nayara Domenicis. Dissertação sobre o instituo da delação premiada. Disponível em: https://naydomenicis.jusbrasil.com.br/artigos/463149186/dissertacaosobre-o-instituo-da-delacao-premiada. Acesso em: 08 de Agosto de 2017. 
QUEIJO, Maria Elizabeth. 0 direito de não produzir prova contra si mesmo: o princípio nemo tenetur se detegere e suas decorrências no processo penal. São Paulo: Saraiva, 2003.

SANTOS, Paulo Dutra. Colaboração unilateral premiada como consectário lógico das balizas constitucionais do devido processo legal brasileiro. Disponível em: http://www.ibraspp.com.br/revista/index.php/RBDPP/article/view/49. Acesso em: 11 de Agosto de 2017.

SANTOS, Luciano Aragão. 0 direito de não produzir prova contra si mesmo: "Nemo tenetur se detegere". Disponível em: http://www.direitonet.com.br/artigos/exibir/5283/O-direito-de-nao-produzir-provacontra-si-mesmo-Nemo-tenetur-se-detegere. Acesso em: 11 de Agosto de 2017.

SIMÕES, Maria Tereza Aranega dos Reis e PEREIRA, Monique Rodrigues Silva Cavalcante. Delação Premiada e a quebra dos princípios constitucionais. Disponível em: https:/terezasim.jusbrasil.com.br/artigos/317388121/delacaopremiada-e-a-quebra-dos-principios-constitucionais. Acesso em: 11 de Agosto de 2017.

VALOR ECONÔMICO. Caso Banestado já soma 19 acordos de delação premiada com doleiros. Disponível

em:

$<$ http://www2.senado.leg.br/bdsf/bitstream/handle/id/479265/noticia.htm?sequence= 1>. Acesso em 10 de agosto de 2017.

ZAFFARONI, Eugenio Raúl. Crime organizado: uma categoria frustrada. Discursos sediciosos: crime, direito e sociedade, Rio de Janeiro, ano 1, v. 1, 1996.

Enviado: Novembro, 2019.

Aprovado: Dezembro, 2019. 